\title{
Preparation, Characterization, and Analytical Application of Ramipril Membrane-Based Ion-Selective Electrode
}

\author{
Hassan Arida, ${ }^{1}$ Mona Ahmed, ${ }^{2}$ and Abdallah $\mathrm{Ali}^{2}$ \\ ${ }^{1}$ Hot Laboratories Center, Atomic Energy Authority, Cairo 13759, Egypt \\ ${ }^{2}$ Girls College, Ain Shams University, Cairo 11757, Egypt \\ Correspondence should be addressed to Hassan Arida, aridaha@hotmail.com
}

Received 10 August 2008; Revised 12 January 2009; Accepted 14 January 2009

Recommended by Jan Åke Jönsson

\begin{abstract}
The fabrication and electrochemical evaluation of two PVC membrane-based Ion-Selective electrodes responsive for ramipril drug have been proposed. The sensitive membranes were prepared using ramipril-phosphomolibdate and ramipril-tetraphenylborate ion-pair complexes as electroactive sensing materials in plasticized PVC support. The electrodes based on these materials provide near-Nernestian response (sensitivity of $53 \pm 0.5-54 \pm 0.5 \mathrm{mV} /$ concentration decade) covering the concentration range of $1.0 \times$ $10^{-2}-1.0 \times 10^{-5} \mathrm{~mol} \mathrm{~L}^{-1}$ with a detection limit of $3.0 \times 10^{-6}-4.0 \times 10^{-6} \mathrm{~mol} \mathrm{~L}^{-1}$. The suggested electrodes have been successfully used in the determination of ramipril drug in some pharmaceutical formulations using direct potentiometry with average recovery of $>96 \%$ and mean standard deviation of $<3 \%(n=5)$.
\end{abstract}

Copyright () 2009 Hassan Arida et al. This is an open access article distributed under the Creative Commons Attribution License, which permits unrestricted use, distribution, and reproduction in any medium, provided the original work is properly cited.

\section{Introduction}

Ramipril (see Scheme 1) contains not less than $98.0 \%$ of $\mathrm{C}_{23} \mathrm{H}_{32} \mathrm{~N}_{2} \mathrm{O}_{5} ; \quad(2 \mathrm{~S}, 3 \mathrm{aS}, 6 \mathrm{aS})-1-[(2 \mathrm{~S})-2-[[(2 \mathrm{~S})-1$-ethoxy-1oxo-4-phenylbutan-2-yl] amino]propanoyl $]-3,3 \mathrm{a}, 4,5,6,6 \mathrm{a}-$ hexahydro-2H-cyclopenta[d]pyrrole-2 carboxylic acid. It belongs in a class of drugs called angiotensin converting enzyme (ACE) inhibitors which are used for treating high blood pressure and heart failure and for preventing kidney failure due to high blood pressure and diabetes. ACE is important because it produces the protein, angiotensin II. Angiotensin II contracts the muscles of most arteries in the body, including the heart, thereby narrowing the arteries and elevating the blood pressure. In the kidney, the narrowing caused by angiotensin II also increases blood pressure and decreases the flow of blood. ACE inhibitors such as ramipril lower blood pressure by reducing the production of angiotensin II, thereby relaxing the arterial muscles and enlarging the arteries. The enlargement of the arteries throughout the body reduces the blood pressure against which the heart must pump blood, and it becomes easier for the heart to pump blood. The arteries supplying the heart with blood also enlarge. This increases the flow of blood and oxygen to the heart, and this improves further the ability of the heart to pump blood. The effects of ACE inhibitors are particularly beneficial to people with congestive heart failure. In the kidneys, the enlargement of the arteries also reduces blood pressure and increases blood flow.

Methods in current use for the assay of ramipril, in pharmaceutical preparation, are based on spectrophotometry [1-6], liquid chromatography [7-12], gas chromatography $[13,14]$, enatioselective biosensors [15], enatioselective membrane [16], voltammetry [17], amperometric biosensor [18], and mass spectrometry [12]. However, most of these methods are sophisticated, tedious, and required many manipulation steps. On the other hand, although, ion-selective electrodes and potentiometric sensors are much simpler, fast, and inexpensive, only one ion-selective electrode has been reported for the determination of ramipril drug as anionic species [19].

In this paper, the preparation, characterization, and analytical application of new two ramipril cationic ionselective electrodes based on phosphomolibdate and tetraphenylborate-ramipril ion-pair complexes have been 


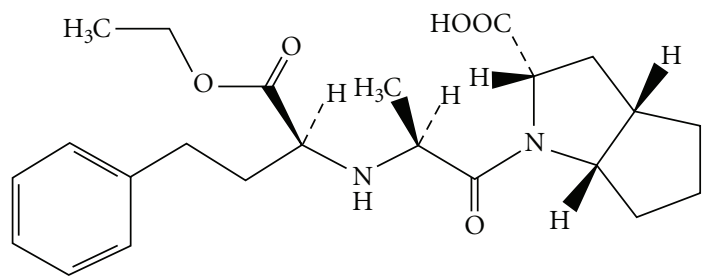

SCHeme 1: Structure of ramipril.

reported. The merits offered by the proposed electrodes include the high cationic sensitivity of the drug in the acid media with fast response time $(<30$ seconds) and long life span (2 months).

\section{Experimental}

2.1. Apparatus. The potentiometric measurements were made at $25 \pm 1^{\circ} \mathrm{C}$, using an Orin (Model A720) digital $\mathrm{pH} / \mathrm{mV}$ meter and Orion Ross Combination $\mathrm{pH}$ electrode (Model 81-02) for all $\mathrm{pH}$ measurements. The suggested ramipril PVC membrane-based electrode was used for all potentiometric measurements in conjunction with a double junction reference electrode (Orion Model 90-02) containing $\mathrm{KNO}_{3}(10 \% \mathrm{w} / \mathrm{v})$ in the outer compartment. Perkin-Elmer (Norwalk, Conn, USA) 1430 ratio recording IR spectrophotometer was used for structure elucidation of the ion-pair complexes.

2.2. Reagents and Materials. All chemicals were of analytical reagent grade unless otherwise stated and doubly distilled water was used throughout. Poly (vinyl chloride) powder (PVC) of high molecular weight (10000) and dioctyl phthalate plasticizer of purity $98 \%$ were obtained from Aldrich chemical company, Inc. (Milwaukee, Wis, USA). Tetrahydrofuran (THF) with a purity of $99 \%$ containing $0.025 \%$ butylatedhydroxytoluene inhibitor was used as solvent.

Ramipril stock solution $\left(10^{-2} \mathrm{~mol} \mathrm{~L}^{-1}\right)$ was prepared by dissolving $0.4165 \mathrm{~g}$ in a minimal volume of acetic acid with continuous stirring and then diluted to 100 mLLwith distilled water. The resulting clear solution of $\mathrm{pH} 3$ was obtained by the addition of small aliquots of $10^{-2} \mathrm{~mol} \mathrm{~L}^{-1}$ $\mathrm{HCl}$. Standard phosphomolibdate and tetraphenylborate solutions $\left(0.2 \mathrm{~mol} \mathrm{~L}^{-1}\right)$ were individually prepared by dissolving appropriate weight of sodium phosphomolibdate and tetraphenylborate, respectively, in a minimum volume of distilled water followed by filtration then completed to $100 \mathrm{~mL}$ with distilled water.

\subsection{The Ramipril Membrane-Based Ion-Selective} Electrodes. Ramipril-phosphomolibdate and ramipriltetraphenylborate ion-pair sensing materials were individually prepared by mixing $30 \mathrm{~mL}$ aliquot of $10^{-2} \mathrm{~mol} \mathrm{~L}^{-1}$ ramipril solution with a $30 \mathrm{~mL}$ aliquot of $10^{-2} \mathrm{~mol} \mathrm{~L}^{-1}$ aqueous phosphomolibdate and tetraphenylborate solutions, respectively in $100 \mathrm{~mL}$ beaker. The obtained precipitates were filtered using a $\mathrm{G}_{4}$ sintered glass crucible, washed thoroughly with distilled water, and dried at room temperature.

Two PVC master membranes based on the suggested sensing materials containing $0.01 \mathrm{~g}$ ion-pair complex, $0.350 \mathrm{~g}$ dioctylphthalate (DOP), and $0.190 \mathrm{~g}$ of poly (vinyl chloride) were individually prepared. Each membrane contents were thoroughly mixed, dissolved in $6 \mathrm{~mL}$ aliquot of THF, and transferred to a glass Petri dish ( $3 \mathrm{~cm}$ diameter). The Petri dish was covered with a filter paper and left to stand overnight to allow slow evaporation of the solvent at room temperature. The membranes were sectioned with a cork borer ( $10 \mathrm{~mm}$ diameter) and attached to a length of polyethylene tubing ( $3 \mathrm{~cm}$ length, $8 \mathrm{~mm}$ i.d) by using THF.

A home -made electrode body was used, which consists of a glass tube, to one end of which the poly ethylene tubing was attached and filled with an equimolar mixture of $10^{-2} \mathrm{~mol} \mathrm{~L}^{-1}$ of potassium chloride and ramipril as the internal reference solution. $\mathrm{An} \mathrm{Ag} / \mathrm{AgC1}$ internal reference wire electrode $(1.0 \mathrm{~mm}$ diameter $)$ was immersed in the internal solution. This assembly was used in the potentiometric characterization of the electrodes and the subsequent determination of the drug.

2.4. Electrochemical Evaluation of the Electrodes. In order to calibrate the suggested electrodes, aliquots $(10 \mathrm{~mL})$ of aqueous ramipril solutions $\left(1.0 \times 10^{-2}-1.0 \times 10^{-7} \mathrm{~mol} \mathrm{~L}^{-1}\right)$ were transferred into $50 \mathrm{~mL}$ beakers, and the PVC membrane electrode, in conjunction with a double junction $\mathrm{Ag} / \mathrm{AgCl}$ reference electrode, was immersed in the solution. Alternatively, the drug PVC membrane electrode in conjunction with a double junction $\mathrm{Ag} / \mathrm{AgC1}$ reference electrode was immersed in a $50 \mathrm{~mL}$ beaker containing a $10 \mathrm{~mL}$ aliquot of water. Aliquots $(1 \mathrm{~mL})$ of $10^{-2}-10^{-6} \mathrm{~mol} \mathrm{~L}^{-1}$ pure drug solution were successively added. The solutions were gently stirred during the measurements and the potential recorded after stabilization to $\pm 0.2 \mathrm{mV}$ and the e.m.f plotted on semilogarithmic paper as a function of the drug concentration. The calibration graphs were used for subsequent determination of unknown concentration of the drug.

The potentiometric selectivity coefficient indicates the extent to which a foreign ion B interferes with the response of the electrode to its primary drug ion A. The potentiometric selectivity coefficients $K_{\mathrm{A}, \mathrm{B}}^{\mathrm{pot}}$ for the suggested electrodes were measured by separate solutions method SSM [20]. In this method, the potential responses of the electrode in $10^{-2} \mathrm{~mol} \mathrm{~L}^{-1}$ solution of the interferents were measured and recorded. The potential response of the electrode for the drug was separately, obtained in a similar manner at the same concentration level. The selectivity coefficient values were calculated using the simplified form of Eisemnan Nicolsky equation:

$$
K_{\mathrm{A}, \mathrm{B}}^{\mathrm{pot}}=\frac{E_{1}-E_{2}}{S}+\left(1-\frac{1}{Z_{2}}\right) \log a_{1}
$$


TABLE 1: Response characteristics of ramipril membrane-based selective electrodes.

\begin{tabular}{lcc}
\hline Parameter & $\begin{array}{c}\text { Ramipril } \\
\text { phosphomolibdate }\end{array}$ & $\begin{array}{c}\text { Ramipril } \\
\text { tetraphenylborate }\end{array}$ \\
\hline Slope, $\mathrm{mV} /$ decade & $53 \pm 0.5$ & $54 \pm 0.5$ \\
Linear range, $\mathrm{mol} \mathrm{L}^{-1}$ & $1 \times 10^{-2}-1 \times 10^{-5}$ & $1 \times 10^{-2}-1 \times 10^{-5}$ \\
Lower limit of detection, & $4.0 \times 10^{-6}$ & $3.0 \times 10^{-6}$ \\
$\mathrm{~mol} \mathrm{~L}^{-1}$ & $<20$ & $<15$ \\
Response time, (s) & 60 & 50 \\
Life time, $(\mathrm{d})$ & $1-3.8$ & $1-4$ \\
Working pH range & & 0 \\
\hline
\end{tabular}

where $E_{1}$ and $E_{2}$ are the potential readings of the electrode in separate solutions of the same concentration of the drug and interferants, respectively, $S$ is the slope of the drug calibration graph ( $\mathrm{mV} /$ concentration decade), $a_{1}$ is the activity of the drug, and $Z_{2}$ is the charge number of the interfering ion.

The effect of $\mathrm{pH}$ of the test solution on the potential reading of the suggested drug electrodes was studied by immersing a Ross combination glass electrode (Orion model 81-02), PVC membrane electrode, and a double junction $\mathrm{Ag} / \mathrm{AgCl}$ reference electrode in $50 \mathrm{~mL}$ beakers containing $30 \mathrm{~mL}$ aliquots of $10^{-3}$ and $10^{-4} \mathrm{~mol} \mathrm{~L}^{-1}$ drug solutions. The $\mathrm{pH}$ of each solution was gradually increased and decreased by adding small aliquots of dilute sodium hydroxide and hydrochloric acid, respectively. The potential at each $\mathrm{pH}$ value was recorded. The $\mathrm{mV}-\mathrm{pH}$ profile at each drug concentration was plotted for the two electrode systems.

2.5. Analytical Application of the Ramipril Electrodes. In order to investigate the reliability of the proposed electrodes, they have been applied in the determination of the drug using direct potentiometry and potentiometric titration. In the direct potentiometry study, a PVC membrane-based ramipril electrode in conjunction with a double junction reference electrode was immersed in a $10 \mathrm{~mL}$ of the appropriate drug solutions of unknown concentration. The potential readings were recorded after stabilization to $\pm 0.2 \mathrm{mV}$ and compared with the calibration graph. The solutions were stirred during measurements, and the electrodes were thoroughly washed with distilled water between measurements.

In the potentiometric titration of ramipril, aliquots (2$6 \mathrm{~mL}$ ) of $10^{-3} \mathrm{~mol} \mathrm{~L}^{-1}$ of ramipril solution were transferred to $50 \mathrm{~mL}$ beakers and diluted to $10 \mathrm{~mL}$ with distilled water. The solution was stirred and titrated with a standard $10^{-3} \mathrm{~mol} \mathrm{~L}^{-1}$ sodium tetraphenylborate solution using the suggested ramipril membrane electrode in conjunction with a double junction $\mathrm{Ag} / \mathrm{AgCl}$ reference electrode. The electrode potential $(E)$ was recorded as a function of the titrant volume $(v)$ added, ( $E$ versus $v$ ) curves were plotted. The end point was calculated from the maximum slope $\Delta E / \Delta v$ versus $v$.

Moreover, different forms and dosages of pharmaceutical preparations were assayed to determine ramipril in different formulations. In this study, aliquot of $5 \mathrm{~mL}$ of the drug was transferred to $25 \mathrm{~mL}$ beaker containing $15 \mathrm{~mL}$ of deionised water, and the $\mathrm{pH}$ of the solution was adjusted to $\mathrm{pH} 3$ with a drop of dilute $\mathrm{HCl}$ solution. The solution was then transferred to $25 \mathrm{~mL}$ volumetric flask, completed to the mark, shaken well, and transferred to a $100 \mathrm{~mL}$ beaker for ISE measurement. For the assay of tablet formulations, 10 tablets were finely powdered, mixed, and an accurate weight equivalent to $0.1 \%$ of the tablet was transferred into $50 \mathrm{~mL}$ beakers containing $20 \mathrm{~mL}$ of deionized water, the $\mathrm{pH}$ of the solution was adjusted to $\mathrm{pH} 3$ with a drop of dilute $\mathrm{HC} 1$ solution, and transferred to $25 \mathrm{~mL}$ volumetric flask, completed with water to the mark, shaken well. The suggested ramipril-based membrane electrode was immersed in conjunction with a double junction $\mathrm{Ag} / \mathrm{AgCl}$ reference electrode into the solution. The potential was measured after a stable reading was obtained and compared with that on a calibration graph previously constructed for standard solutions.

\section{Results and Discussion}

3.1. The Nature and Composition of Ramipril-Based Membranes. Ramipril-phosphomolibdate and ramipriltetraphenylborate ion-pair complexes have been prepared and examined as new electroactive ionophores in PVC matrix membranes responsive to ramipril cation. In acid media, ramipril cations readily react with phosphomolibdate and tetraphenylborate anions to form stable water insoluble ion association complexes. The IR studies confirm that the formation of 1:1 ramiprilanion ion-pair association. The potentiometric response characteristics of the proposed electrodes were evaluated, according to IUPAC recommendations [20] using the following electrochemical cell:

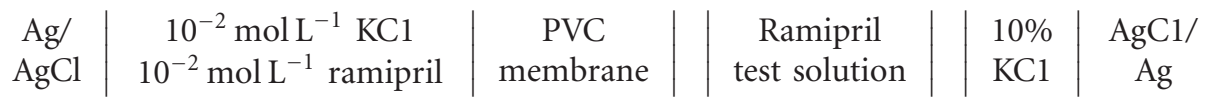




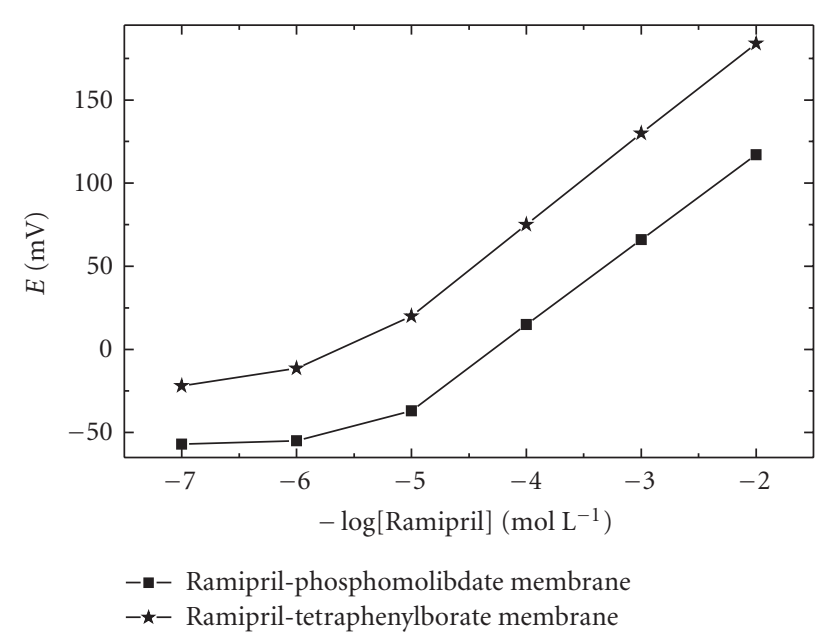

Figure 1: Potentiometric calibration response of ramibril-based selective electrodes.

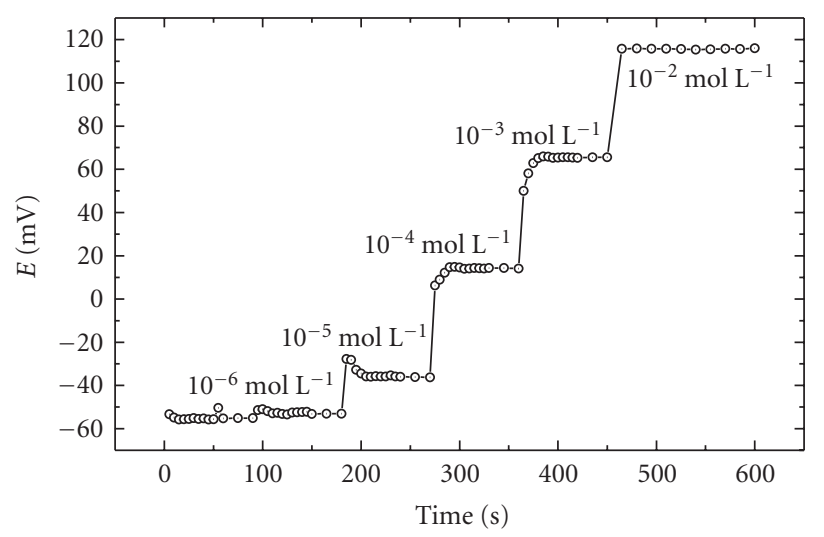

Figure 2: Potentiometric dynamic response of ramiprilphosphomolibdate membrane electrode.

3.2. Electrochemical Evaluation of Ramipril Electrodes. The potentiometric response characteristics of the investigated ramipril PVC membrane-based electrodes were evaluated from the data collected from four assemblies for each membrane electrode. The results are summarized in (Table 1). The responses of ramipril electrode systems are linear over the concentration range $1 \times 10^{-2}-1 \times 10^{-5} \mathrm{~mol} \mathrm{~L}^{-1}$. The slopes of the calibration plots (Figure 1) are typically 53 $\pm 0.5 \mathrm{mV}$ and $54 \pm 0.5$ per concentration decade for ramipril—phosphomolibdate and ramipril—tetraphenyle borate membrane electrode, respectively. Deviation from the ideal Nernstian slope (59.2 $\mathrm{mV} /$ concentration decade) stems from the fact that most potentiometric drug sensors respond to the activity of the drug cations rather than the concentration.

The response time and stability of the membranes have been investigated. In these studies, the time required for ramipril poly (vinyl chloride) membrane electrodes to reach a value of $\pm 1 \mathrm{mV}$ from the final equilibrium potential in the same day after successive immersion in different ramipril

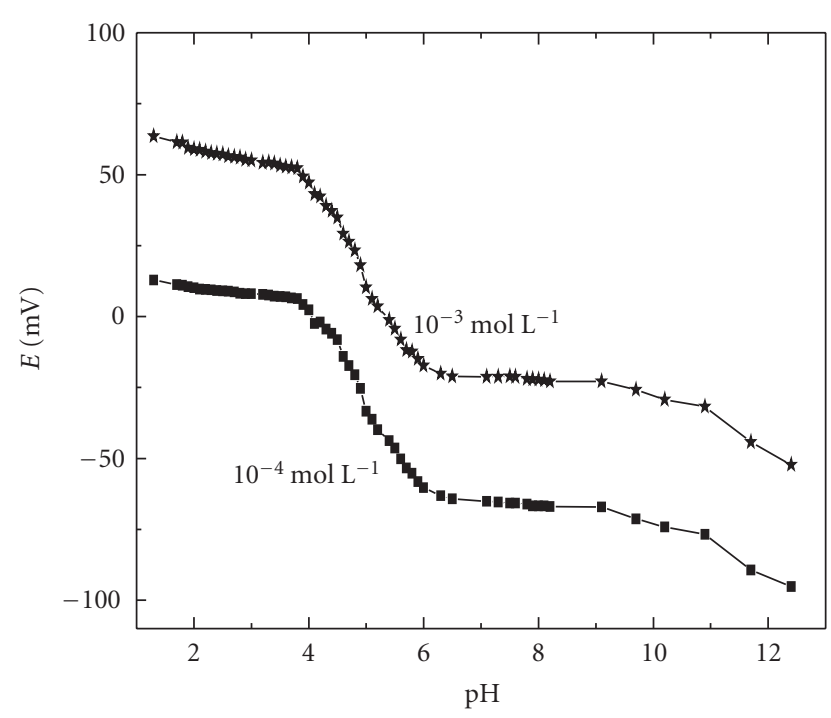

FIGURE 3: Effect of $\mathrm{pH}$ on the potentiometric response of ramiprilphosphomolibdate PVC membrane electrode.

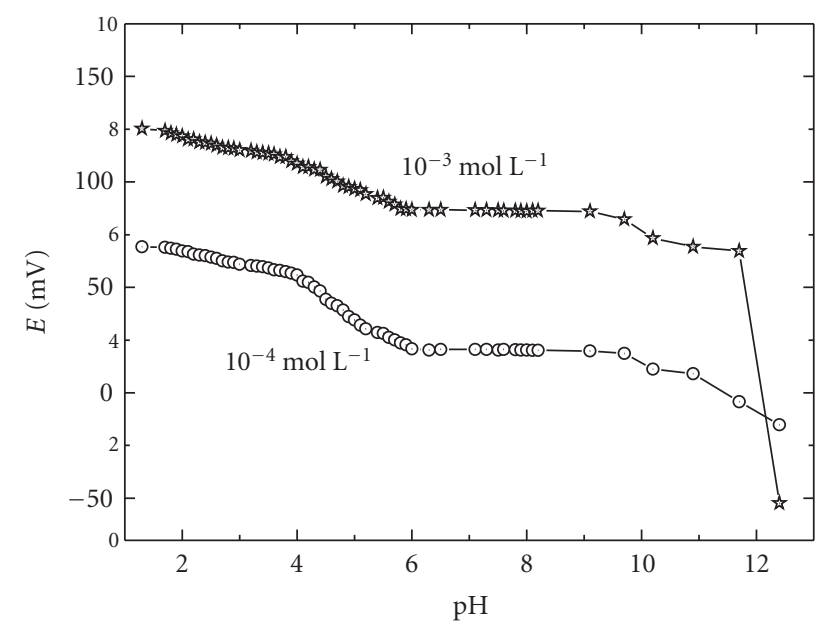

FIGURE 4: Effect of $\mathrm{pH}$ on the potentiometric response of the ramipril-tetraphenylborate PVC membrane electrode.

solutions was measured. The results obtained (Figure 2) show thats the electrode attain stable potential values within 20 seconds. In addition, the potentials displayed by the electrode in the linear concentration range of ramipril in the same day do not vary by more than $\pm 0.5 \mathrm{mV}$. The stability of the potential reading for the ramipril-based electrodes is within $\pm 2 \mathrm{mV}$ during the lifetime (2 months) of the electrodes.

The effect of $\mathrm{pH}$ on the potential readings of the proposed electrode was also examined by recording the e.m.f. of ramipril test solutions $\left(10^{-3}\right.$ and $\left.10^{-4} \mathrm{~mol} \mathrm{~L}^{-1}\right)$ at various $\mathrm{pH}$ values, which were obtained by the addition of very small volumes of hydrochloric acid and/or sodium hydroxide solutions $10^{-1} \mathrm{~mol} / \mathrm{L}$ of each. The e.m.f. $-\mathrm{pH}$ plots presented in Figures 3 and 4 revealed that the potential readings are insensitive to $\mathrm{pH}$ changes in the ranges $1.0-3.8$ and 
TABle 2: Potentiometric selectivity coefficients $\left(K_{\mathrm{A}, \mathrm{B}}^{\mathrm{pot}}\right)$ for the ramipril phosphomolibdate and ramipril-tetraphenylborate selective electrodes.

\begin{tabular}{|c|c|c|}
\hline Interfering species, $\mathrm{B}$ & $\begin{array}{l}\text { Ramipril-phosphomolibdate } \\
\text { electrode }\end{array}$ & $\begin{array}{c}\text { Ramipril-tetraphenylborate } \\
\text { electrode }\end{array}$ \\
\hline Ramipril & 1 & 1 \\
\hline $\mathrm{NH}_{4}^{+}$ & $8.8 \times 10^{-3}$ & $9.1 \times 10^{-3}$ \\
\hline $\mathrm{Co}^{2+}$ & $8.7 \times 10^{-3}$ & $8.8 \times 10^{-3}$ \\
\hline $\mathrm{Cd}^{2+}$ & $8.8 \times 10^{-3}$ & $8.7 \times 10^{-3}$ \\
\hline $\mathrm{Ni}^{2+}$ & $8.8 \times 10^{-3}$ & $8.7 \times 10^{-3}$ \\
\hline $\mathrm{Cr}^{3+}$ & $4.2 \times 10^{-2}$ & $4.3 \times 10^{-2}$ \\
\hline $\mathrm{Cu}^{2+}$ & $6.6 \times 10^{-3}$ & $9.0 \times 10^{-3}$ \\
\hline $\mathrm{Ca}^{2+}$ & $4.6 \times 10^{-3}$ & $4.8 \times 10^{-3}$ \\
\hline $\mathrm{Mg}^{2+}$ & $9.8 \times 10^{-3}$ & $9.8 \times 10^{-3}$ \\
\hline $\mathrm{Sn}^{2+}$ & $5.1 \times 10^{-2}$ & $5.3 \times 10^{-2}$ \\
\hline $\mathrm{K}^{+}$ & $8.8 \times 10^{-3}$ & $8.6 \times 10^{-3}$ \\
\hline $\mathrm{Na}^{+}$ & $8.1 \times 10^{-3}$ & $8.5 \times 10^{-3}$ \\
\hline $\mathrm{Fe}^{3+}$ & $8.8 \times 10^{-3}$ & $8.8 \times 10^{-3}$ \\
\hline Glycine & $7.8 \times 10^{-3}$ & $8.1 \times 10^{-3}$ \\
\hline Phenyl hydrazine & $3.2 \times 10^{-2}$ & $3.2 \times 10^{-2}$ \\
\hline Hydroxylamine & $2.2 \times 10^{-2}$ & $2.7 \times 10^{-2}$ \\
\hline
\end{tabular}

TABLE 3: The accuracy and reliability of result obtained with ramipril PVC matrix membrane electrode.

\begin{tabular}{|c|c|c|c|c|c|}
\hline \multirow[t]{2}{*}{ Sample } & \multirow[t]{2}{*}{ Concentration, $\mathrm{mol} \mathrm{L}^{-1}$} & \multicolumn{2}{|c|}{ Ramipril-phosphomolibdate } & \multicolumn{2}{|c|}{ Ramipril-teraphenylborate } \\
\hline & & Found & Recovery \% & Found & Recovery \% \\
\hline 1 & $1 \times 10^{-3}$ & $0.95 \times 10^{-3}$ & 95.0 & $0.95 \times 10^{-3}$ & 95.0 \\
\hline 2 & $2 \times 10^{-3}$ & $1.87 \times 10^{-3}$ & 93.5 & $1.90 \times 10^{-3}$ & 95.0 \\
\hline 3 & $3 \times 10^{-3}$ & $2.91 \times 10^{-3}$ & 97.0 & $2.92 \times 10^{-3}$ & 97.3 \\
\hline 4 & $4 \times 10^{-3}$ & $3.94 \times 10^{-3}$ & 98.5 & $3.94 \times 10^{-3}$ & 98.5 \\
\hline 5 & $5 \times 10^{-3}$ & $4.98 \times 10^{-3}$ & 99.6 & $4.93 \times 10^{-3}$ & 98.6 \\
\hline & ragere covery & & 96.7 & & 96.9 \\
\hline
\end{tabular}

1.0-4.0 for the ramipril-phosphomolibdate and ramipeiltetraphenylborate, respectively. The shape of $\mathrm{mV}-\mathrm{pH}$ profile depends on the stability of the ion-pair in the membrane as a function of $\mathrm{pH}$, the nature of the drug (protonation or complexation equilibrium) in the test solution, and the sensitivity of the membrane to either $\left[\mathrm{H}^{+}\right]$or $\left[\mathrm{OH}^{-}\right]$at low or high $\mathrm{pH}$ values, respectively. It was observed that ramipril ion-pair complexes deteriorate in alkaline media causing severe potential shift. At relatively higher $\mathrm{pH}$ values, the e.m.f decreased this is probably due to deprotonated species in test solution.

The selectivity coefficients of the investigated electrodes were evaluated using separate solution method (SSM). In this study, the performance of the ramipril electrodes in the presence of some tested organic and inorganic cations was studied. The selectivity coefficient values $\left(K_{\mathrm{A}, \mathrm{B}}^{\mathrm{pot}}\right)$ are calculated and presented in Table 2 . As can be seen, the electrode offers a reasonable selectivity for the ramipril cation over most of the tested species.

3.3. Analytical Application of Ramipril Electrodes. In order to investigate the analytical usefulness of the proposed electrodes, they have been successfully applied in the potentiometer determination of ramipril in aqueous samples as well as in some local pharmaceutical formulations. In the former study, solutions of concentration in the liner range of the tested electrode are prepared from pharmaceutical grade of ramipril and determined by direct potentiometry and potentiometric titration using the proposed ramipril electrodes. The results obtained are summarized in Table 3. In the later study, some local pharmaceutical formulations have been prepared and analyzed by direct potentiometry using the investigated ramipril electrodes. The results obtained are summarized in Table 4 . As can be seen, the 
TABLE 4: Determination of ramipril in some pharmaceutical preparations.

\begin{tabular}{|c|c|c|c|c|c|}
\hline \multirow[t]{2}{*}{ Sample ${ }^{(a)}$} & \multirow[t]{2}{*}{ Nominal content $\mathrm{mg} /$ tablet } & \multicolumn{2}{|c|}{ Ramipril-phosphomolibdate } & \multicolumn{2}{|c|}{ Ramipril-teraphenylborate } \\
\hline & & Found & Recovery \% & Found & Recovery \% \\
\hline 1 & 1.25 & 1.23 & 98.4 & 1.24 & 99.2 \\
\hline 2 & 2.50 & 2.43 & 97.2 & 2.46 & 98.4 \\
\hline 3 & 5.0 & 4.95 & 99.0 & 4.95 & 99.0 \\
\hline & erage recovery & & 98.2 & & 98.8 \\
\hline
\end{tabular}

(a) Different pharmaceutical formulations (tritace; aventis).

two electrodes provide a good accuracy (average recovery $>96 \%$ ) and high precision ( $\mathrm{RSD}<3 \%, n=5$ ) in both studies.

\section{Conclusion}

Two ramipril selective electrodes have been prepared and electrochemicaly evaluated. They provide analytical, useful sensitivity to the drug with fast response time, reliable, and reproducible response. The proposed electrodes have been successfully applied in the determination of ramipril in some pharmaceutical formulations with good accuracy and high precision.

\section{References}

[1] S. M. Blaih, H. H. Abdine, F. A. El-Yazbi, and R. A. Shaalan, "Spectrophotometric determination of enalapril maleate and ramipril in dosage forms," Spectroscopy Letters, vol. 33, no. 1, pp. 91-102, 2000.

[2] H. H. Abdine, F. A. El-Yazbi, R. A. Shaalan, and S. M. Blaih, "Direct, differential solubility and compensatory-derivative spectrophotometric methods for resolving and subsequently determining binary mixtures of some antihypertensive drugs," S.T.P. Pharma Sciences, vol. 9, no. 6, pp. 587-591, 1999.

[3] D. Bonazzi, R. Gotti, V. Andrisano, and V. Cavrini, "Analysis of ACE inhibitors in pharmaceutical dosage forms by derivative UV spectroscopy and liquid chromatography (HPLC)," Journal of Pharmaceutical and Biomedical Analysis, vol. 16, no. 3, pp. 431-438, 1997.

[4] H. E. Abdellatef, M. M. Ayad, and E. A. Taha, "Spectrophotometric and atomic absorption spectrometric determination of ramipril and perindopril through ternary complex formation with eosin and $\mathrm{Cu}(\mathrm{II})$," Journal of Pharmaceutical and Biomedical Analysis, vol. 18, no. 6, pp. 1021-1027, 1999.

[5] M. M. Ayad, A. A. Shalaby, H. E. Abdellatef, and M. M. Hosny, "Spectrophotometric and AAS determination of ramipril and enalapril through ternary complex formation," Journal of Pharmaceutical and Biomedical Analysis, vol. 28, no. 2, pp. 311-321, 2002.

[6] N. Rahman, Y. Ahmad, and S. N. H. Azmi, "Kinetic spectrophotometric method for the determination of ramipril in pharmaceutical formulations," AAPS PharmSciTech, vol. 6, no. 3, pp. E543-E551, 2005.

[7] H. Y Aboul-Enein and C. Thiffault, "Determination of ramipril and its precursors by reverse phase high performance liquid chromatography," Analytical Letters, vol. 24, no. 12, pp. 2217-2224, 1991.

[8] M. Ito, T. Kuriki, J. Goto, and T. Nambara, "Separation of ramipril optical isomers by high-performance liquid chromatography," Journal of Liquid Chromatography, vol. 13, no. 5, pp. 991-1000, 1990.

[9] U. J. Dhorda and N. B. Shetkar, "Reverse phase HPLC determination of ramipril and amlodipine in tablets," Indian Drugs, vol. 36, pp. 638-641, 1999.

[10] R. Bhushan, D. Gupta, and S. K. Singh, "Liquid chromatographic separation and UV determination of certain antihypertensive agents," Biomedical Chromatography, vol. 20, no. 2, pp. 217-224, 2006.

[11] F. Belal, I. A. Al-Zaagi, E. A. Gadkariem, and M. A. Abounassif, "A stability-indicating LC method for the simultaneous determination of ramipril and hydrochlorothiazide in dosage forms," Journal of Pharmaceutical and Biomedical Analysis, vol. 24, no. 3, pp. 335-342, 2001.

[12] Z. Zhu, A. Vachareau, and L. Neirinck, "Liquid chromatography-mass spectrometry method for determination of ramipril and its active metabolite ramiprilat in human plasma," Journal of Chromatography B, vol. 779, no. 2, pp. 297-306, 2002.

[13] K. M. Sereda, T. C. Hardman, M. R. Dilloway, and A. F. Lant, "Development of a method for the detection of angiotensin-converting enzyme," Analytical Proceedings, vol. 30, no. 9, p. 371, 1993.

[14] D. Schmidt, K.-U. Weithmann, V. Schlotte, and D. Riecke, "Hochempfindliche GC/MS-Methode zur Bestimmung des stabilen Prostacyclin Metaboliten 6-oxo-PGF $1 \alpha$ in Humanurin," Fresenius' Journal of Analytical Chemistry, vol. 320, no. 7, p. 732, 1985.

[15] R.-I. Stefan, J. F. van Staden, and H. Y. Aboul-Enein, "Analysis of chiral drugs with enantioselective biosensors. An overview," Electroanalysis, vol. 11, no. 16, pp. 1233-1235, 1999.

[16] P. Shahgaldian and U. Pieles, "Cyclodextrin derivatives as chiral supramolecular receptors for enantioselective sensing," Sensors, vol. 6, no. 6, pp. 593-615, 2006.

[17] A. A. Al-Majed, F. Belal, A. Abadi, and A. M. Al-Obaid, "The voltammetric study and determination of ramipril in dosage forms and biological fluids," Farmaco, vol. 55, no. 3, pp. 233238, 2000.

[18] R.-I. Stefan, J. F. van Staden, C. Bala, and H. Y. Aboul-Enein, "On-line assay of the $S$-enantiomers of enalapril, ramipril and pentopril using a sequential injection analysis/amperometric biosensor system," Journal of Pharmaceutical and Biomedical Analysis, vol. 36, no. 4, pp. 889-892, 2004. 
[19] H. Y. Aboul-Enein, A. A. Bunaciu, C. Bala, and S. Fleschin, "Enalapril and ramipril selective membranes," Analytical Letters, vol. 30, no. 11, pp. 1999-2008, 1997.

[20] Y. Umezawa, K. Umezawa, and H. Sato, "Selectivity coefficients for ion-selective electrodes: recommended methods for reporting $K_{\mathrm{A}, \mathrm{B}}^{\mathrm{pot}}$ values," Pure and Applied Chemistry, vol. 67, no. 3, pp. 507-518, 1995. 


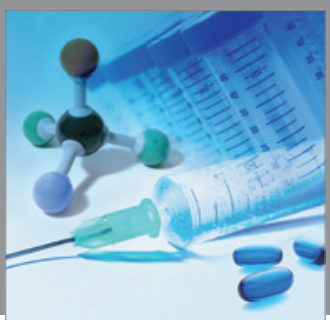

International Journal of

Medicinal Chemistry

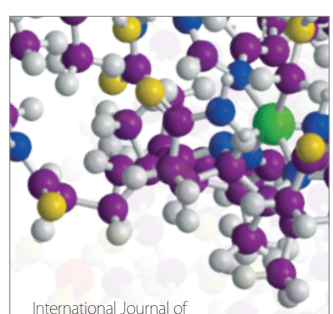

Carbohydrate Chemistry

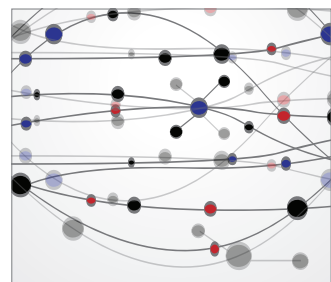

The Scientific World Journal
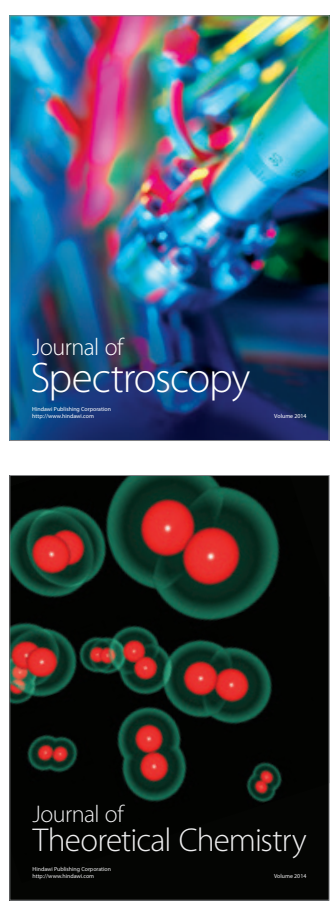
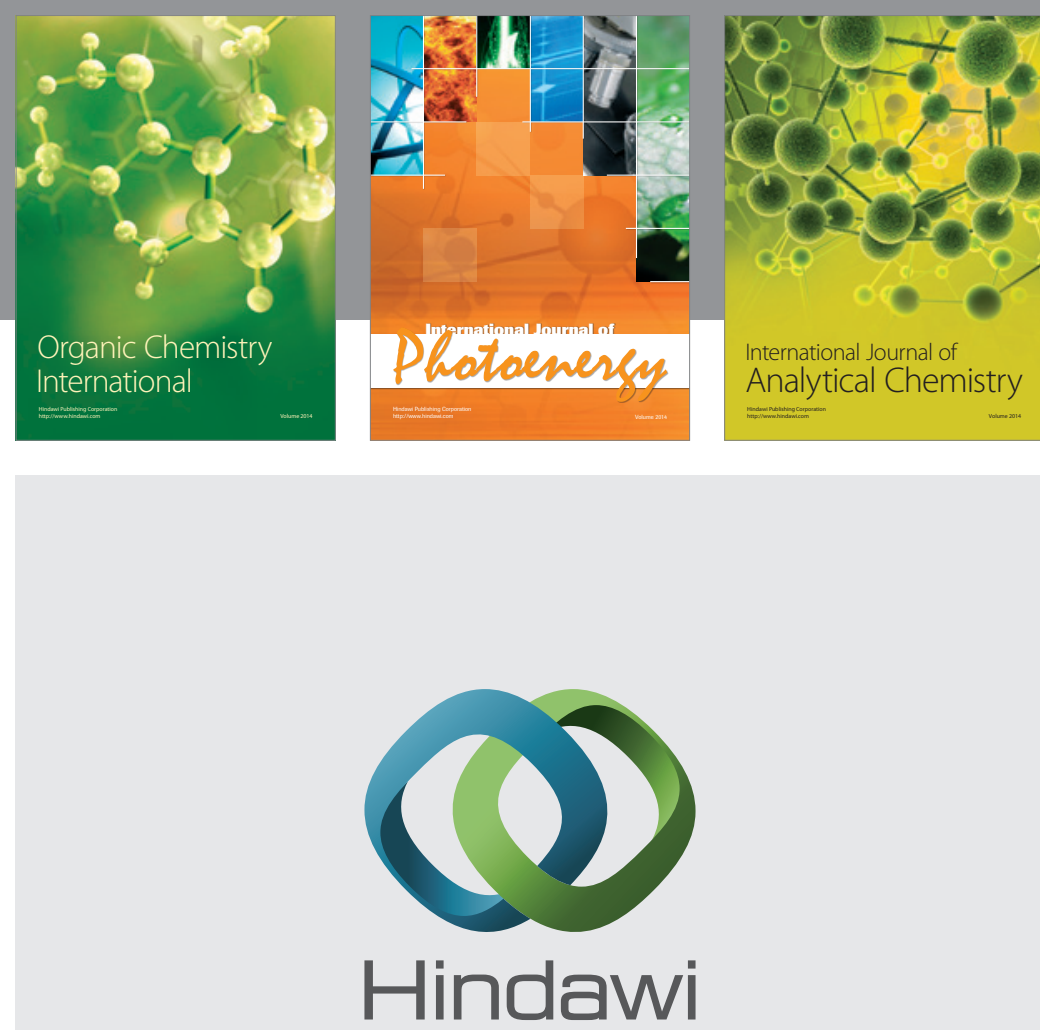

Submit your manuscripts at

http://www.hindawi.com
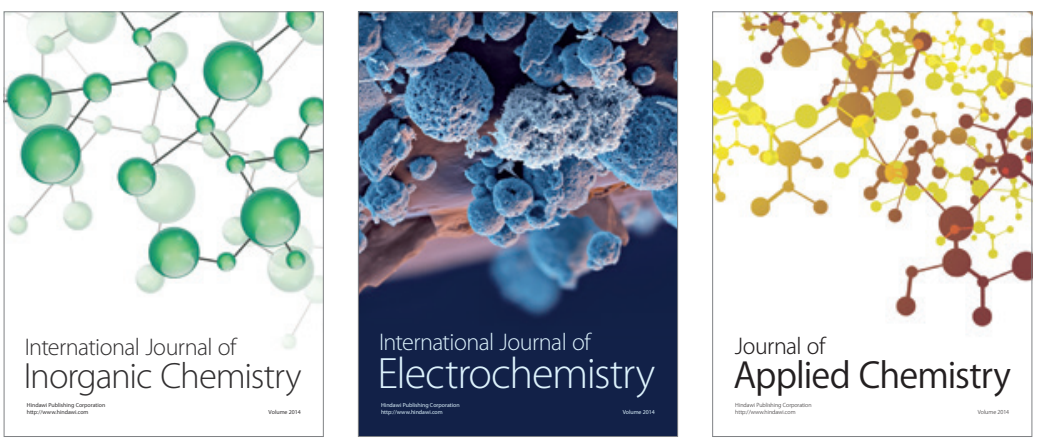

Journal of

Applied Chemistry
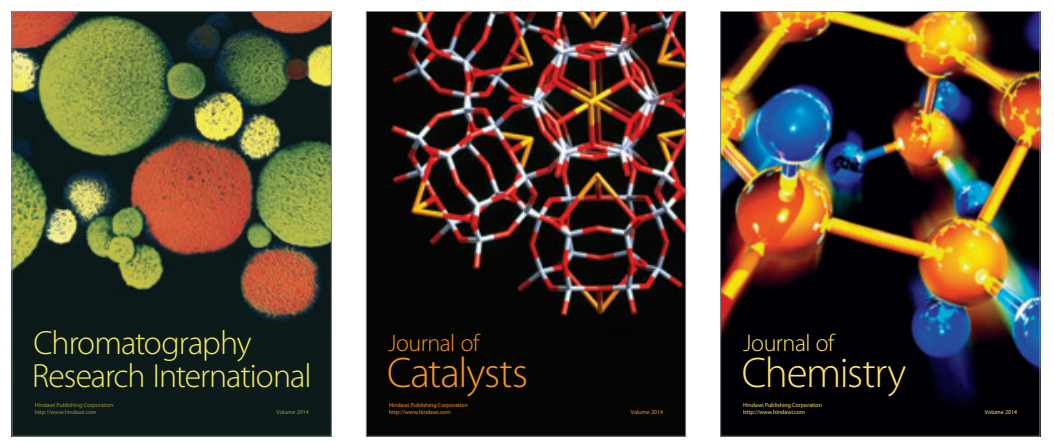
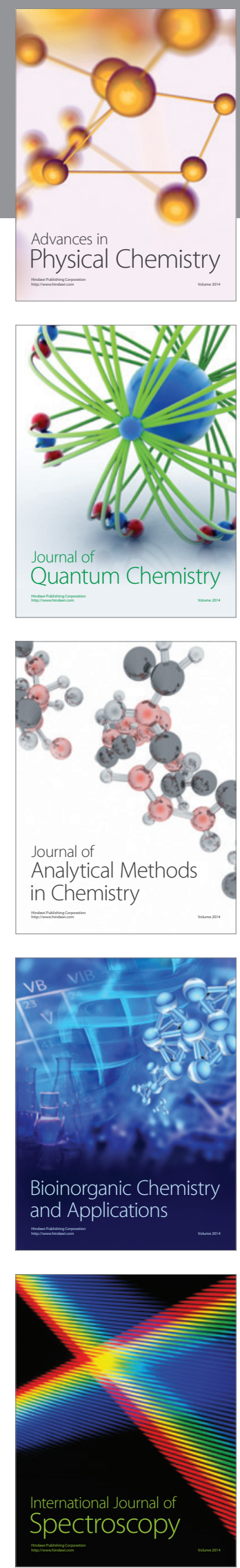